\title{
Studying the Interaction between a New Mixture in Enhancing Drag Reduction Efficiency
}

\author{
Hayder A. Bari and Emsalem Faraj
}

\begin{abstract}
Polymers are used as drag reducer in a strategic pipeline successfully for the past few decades due to its viscoelastic properties that can suppress the turbulent in pipelines. One of the many issues facing the use of these additives is its resistance to high shear forces during the transportation where it can be easily degraded where they pass them a pump. In the present work, polymer-surfactant complexes of anionic polymer and nonionic surfactant are investigated to prove its capability in enhancing the drag reduction and mechanism degradation performance. The interaction between anionic polymer Poly (acrylamide-codiallyl-dimethylammonium chloride) and nonionic surfactant tween 20 in aqueous solution has been studied by using rheology, rotating disk apparatus (RDA) and pipe loop techniques. The effect of polymer concentration, surfactant concentration and rotational speed in enhancing the drag reduction were studied. The results showed that almost $35 \%$ drag reduction can be obtained. In addition, the effect of the degradation on the mixtures as a function in the time has been discussed also.
\end{abstract}

Index Terms-Polymer, surfactant, drag reduction, RDA.

\section{INTRODUCTION}

Drag reduction (DR) has wide applications in industry such as; transportation of oil, wastewater treatment, firefighting, transport of solids in water, heating and cooling rings, hydraulic and jet machinery, and also biomedical applications [1]-[4].

A lot of research work has been done to enhance the DR efficiency of fluids by using Polymer additives (PAs) after Dodge and Metzner studies [5]. Lumley [6] suggested that there is a serious value of wall shear stress at which the macromolecules become stretched due to the fluctuating strain rate. Though, in the viscous sub-layer close to the wall, polymer coils are not greatly twisted and viscosity does not rise greatly above solvent viscosity. Lumley [7] concluded that the stretching of randomly coiled polymers due to robust turbulent flow is pertinent for DR. Difference in turbulent construction in the buffer layer was also investigated by Tiederman [8]. Virk [9] based on experimental results suggested that DR is incomplete by an asymptotic value. Warholic et al. [10] lead experiments with polymer solutions and concluded that the Reynolds shear stress becomes insignificant near the maximum DR asymptote. Polymer DR was also clarified by viscoelastic effects of the polymer chains in the solution [11], [12]. Tesauro et al. [13] proposed that energy is transported by the velocity fluctuations to the polymer chain; which is kept in the form of stretching of the polymer chain (which in turn wastes the energy into heat), and by easing of the polymer chain from extended to an equilibrium state. But these DR additives are found to be exposed to mechanical and thermal degradation [14] leading to a damage in the drag reduction effectiveness at strong shear forces or a high temperature. Especially it has been well reported that polymer chains are degraded by severe mechanical force in a turbulent flow field.

Several studies [15]-[18] found that the addition of surfactant into a polymer solution could be an active technique in decreasing the mechanical degradation of polymer particularly in high temperature flow systems. The precise mechanism of DR by surfactant solutions is still indistinct; though, certain researchers have proposed that viscoelastic effects of surfactant solution could be accountable for turbulent DR [19]. Polymer and surfactants interact in two ways. First, the interaction is possible for polymers with negative or positive charge with oppositely charged ionic surfactant. The electrostatic interactions play a deep role here. Critical aggregation concentration (CAC) has been reported to be some orders of magnitudes lower than the critical micelle concentration in this case. The interaction between non-ionic polymer and ionic surfactant or (similar charge) polymer-surfactant complex is the second conceivable interaction type, where the CAC can be near to the critical micelle concentration (CMC) of surfactant. A hydrophobic interaction between the hydrophobic portions of both polymer and surfactant is the driving force for the interaction with this type [20]-[23].

The interaction between ionic polymer and ionic surfactant complex (similar charge) has studied by Kim et al. [23]. They found that the \% DR has been increased by adding a little of surfactant to the mixture. That increasing in the \% DR was happened as a result of the hydrophopic interaction between polymer and surfactant.

One aim of this work is to investigate the drag reduction capability of polymer-surfactant complexes. The interaction between anionic polymer Poly (acrylamide-co-diallyldimethylammonium chloride) and nonionic surfactant tween 20 in aqueous solution has been studied by using rheology and RDA techniques. The effect of polymer, surfactant and rotational speed has been discussed. In addition, the effect of the degradation on the pressure drop also has been studied as a function of the time by using flow pipe loop.

\section{MATERIAL AND METHODS}

Manuscript received September 25, 2014; revised November 24, 2014

Hayder A. Bari and Emsalem Faraj are with University Malaysia Pahang, Faculty of Chemical and Natural Resources Engineering, Pahang, Malaysia (e-mail: Hayder.bari@gmail.com, emsalemfrg@yahoo.com).

\section{A. Material}

The Poly (acrylamide-co-diallyl-dimethylammonium 
chloride) (P (AAm-co DADMAC)) 10 wt. $\%$ in $\mathrm{H}_{2} \mathrm{O}$ and Tween 20 were purchased from Sigma Aldrich, they were used without further purification. Double deionized water was used to prepare samples and make dilutions, accordingly.

\section{B. Method}

\section{1) Rheology test}

In this research, the samples from polymer-surfactant mixture were prepared in different concentrations $50,500,700$ and $1000 \mathrm{ppm}$ by using $200 \mathrm{ml}$ of DI water. The samples were left 24 hours until dissolved exactly. The pure water has examined in the Brookfield Viscometer, and then the samples were also examined at the same apparatus to check the viscosity, shear rate and shear stress at (20,40,60, 100, 120, 180 and $200 \mathrm{RPM})$. The temperature was kept at $25^{\circ} \mathrm{C} \pm 0.05^{\circ} \mathrm{C}$.

\section{2) Rotating disk apparatus}

After step of rheology test another samples were prepared also by the same method but by using $1200 \mathrm{ml}$ of the water. The pure water was examined at the rotating disk apparatus (RDA) to check the torque by changing the RPM from 50 to 3000 and these samples also were examined at the rotating disk apparatuses to check the torque for all samples at different RPM. The Fig. 1 is shown the image of rotating disk apparatus.

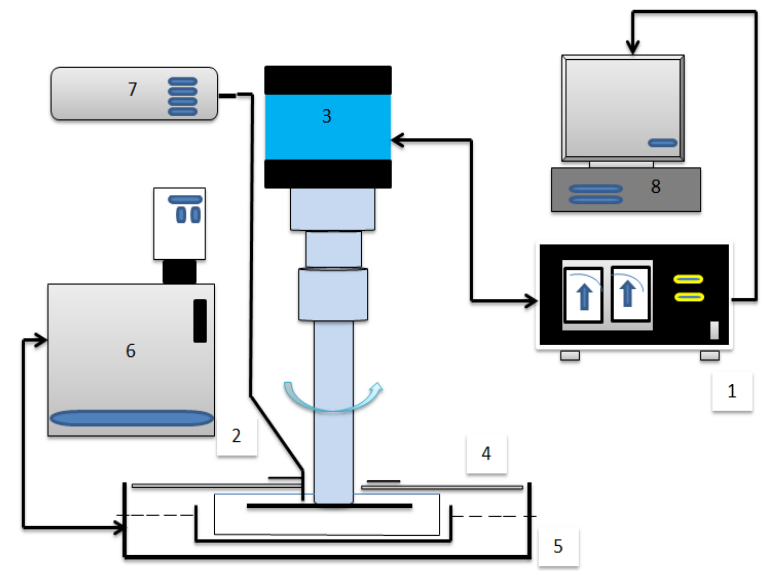

Fig. 1. Graphical image of a rotating disk apparatus for drag reduction measurement: (1) speed controller, (2) thermocouple, (3) motor, (4) solution container, (5) water bath, (6) water-circulating system, (7) thermometer, and (8) PC.

\section{3) Pipe loop}

In this study, the pipe loop was also employed to simulate the pressure drop versus the time. Samples were prepared as previously, with the same concentration parameters $(50,200$, 500,700 and 1000) ppm, respectively in the tap water but with cylinder capacity $(100 \mathrm{~L})$. The samples and the reference were examined at the pipe loop apparatus to measure pressure drop versus the time to compare between pressure drop of water and the samples.

\section{RESULT AND DISCUSSION}

Fig. 2 shows the effect of increasing the concentration of PAMC on the torque comparing the torque of reference (pure water). It can be seen that the torque of PAMC declined dramatically by increasing the concentration compared the torque of the reference. The torque of the water at $3000 \mathrm{rpm}$ was 33 while the torque of PAMC at 50 ppm was 30 at the same rpm. On the other hand, by increasing the concentration of PAMC till 700, $1000 \mathrm{ppm}$ the torque has been decreased to achieve 24,22 respectively.

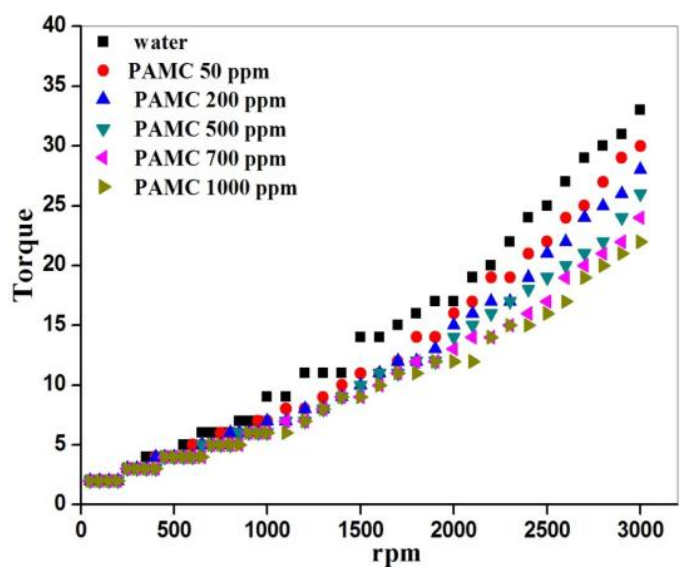

Fig. 2. Effect of concentration on torque as a function of rotational speed of Poly (acrylamide-co-diallyl-dimethylammonium chloride.

Fig. 3. illustrates the relationship between the torque and the rotational speed at different concentration of the Tween 20. It's obvious that the torque of The tween 20 was not affected by increasing the concentration. By increasing the concentration of the tween 20 from 50 to $1000 \mathrm{ppm}$ the torque was exactly same.

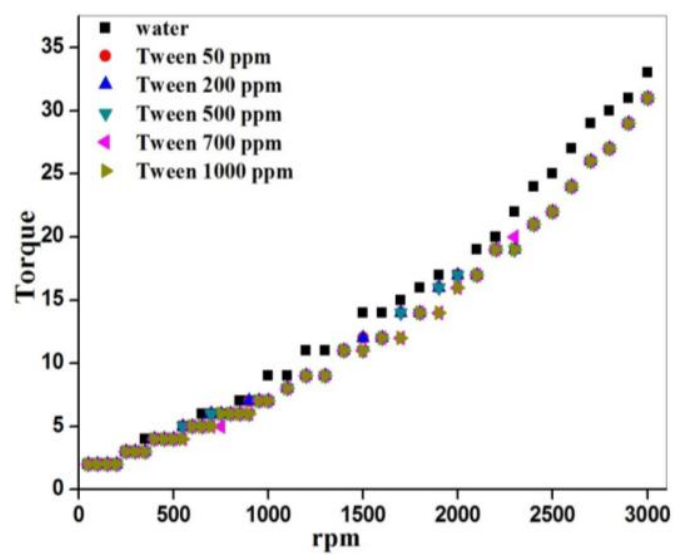

Fig. 3. Effect of concentration on the torque as a function of rotational speed of Tween 20 .

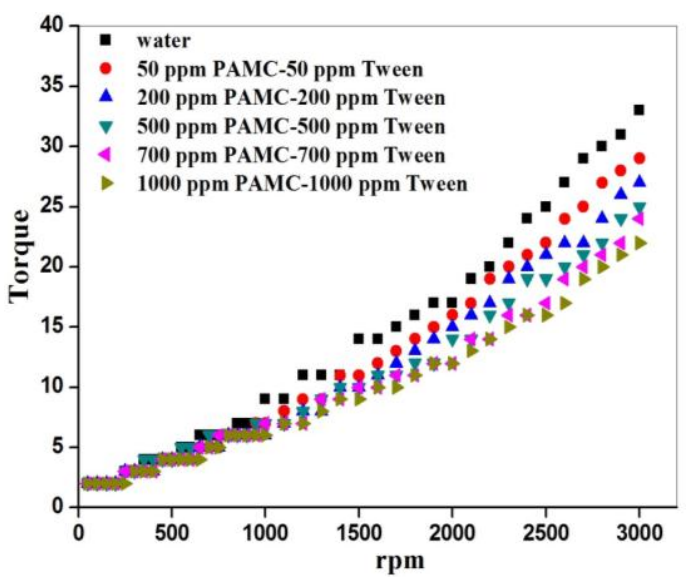

Fig. 4. Effect of concentration on torque as a function of rotational speed of Poly (acrylamide-co-diallyl-dimethylammonium chloride - Tween 20 mixture in water solution.

The relationship between the torque of the reference and mixtures of PAMC-Tween 20 in water solution as a function 
in rpm is shown in Fig. 4. It is obvious that the torque of mixtures has been declined by increasing the concentration. The torque of PAMC-Tween 20 mixture at $3000 \mathrm{rpm}$ and $500 \mathrm{ppm}$ was 25 while the torque of PAMC was 26 at same conditions. This decreasing in the torque was happened as a result of hydrophobic interaction between polymer surfactant mixtures [24]. We can see this interaction as a result of TEM test in Fig. 5.

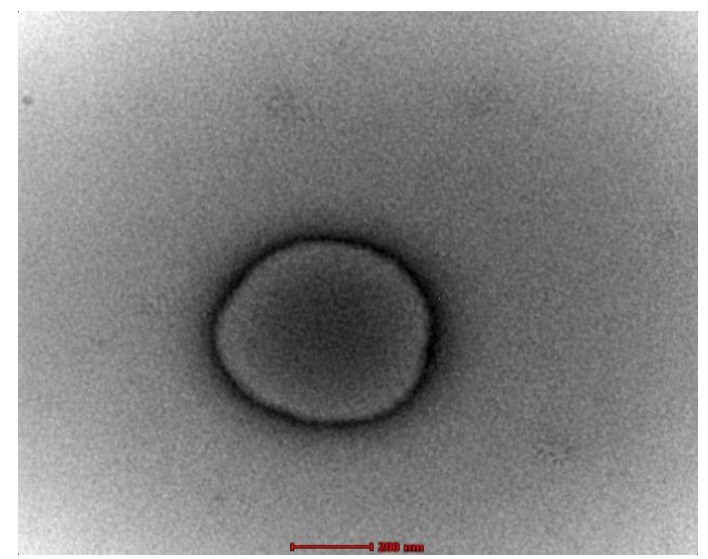

Fig. 5. TEM image of PAMC - Tween mixture at $1000 \mathrm{ppm}$.

Fig. 6 shows the comparison between pressure drop values of reference and polymer surfactant mixtures as a function of time. It can be seen that the $\Delta \mathrm{P}$ decreased by increasing the concentration of the mixtures. The pressure drop of reference was around $101 \mathrm{~Pa}$, while $\Delta \mathrm{P}$ of the mixture 50 ppm PAMC- 50 ppm Tween was almost $99 \mathrm{~Pa}$ during the first $10 \mathrm{~S}$, after that it was decreased slightly until $97 \mathrm{~Pa}$. By increasing the mixture concentration to $1000 \mathrm{ppm}$ the $\Delta \mathrm{P}$ has been declined to around $90 \mathrm{~Pa}$. This decreasing in the pressure drop of the mixture may be happened because the hydrophobic interaction between polymer and surfactant.

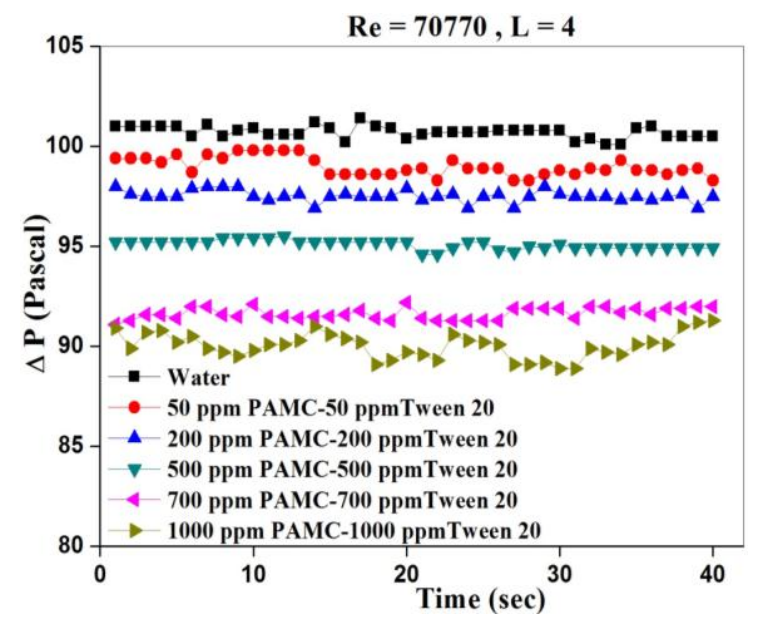

Fig. 6. Compare the values of the pressure drop of reference (tap water) and PAMC - Tween 20 mixtures as a function of time.

\section{CONCLUSION}

In summary, by using a rotating disk apparatus, the effect of surfactant, concentration and rotating speed for ionic polymer of the PAMC on the drag reduction was investigated. The DR efficacy induced by the PAMCTween mixture is found to be obvious higher than that of pure PAMC. In addition, the effect of the degradation on the pressure drop as a function of time was also investigated.

\section{ACKNOWLEDGMENT}

The authors are grateful to University Malaysia Pahang, for financial assistance.

\section{REFERENCES}

[1] D. F. Anghel, J. L. T. Herrera, F. M. Winnik, W. Rettig, and R. V. Klitzing, "Steady state fluorescence investigation of pyrene labeled poly(acrylic acid)s in aqueous solution and in the presence of sodium dodecyl sulfate," Langmuir, vol. 18, pp. 5600-5606, 2002.

[2] H. Diamant and D. Andelman, "Onset of self-assembly in polymersurfactant systems," EPL (Europhysics Letters), vol. 48, pp. 170, 1999.

[3] D. Dodge and A. Metzner, "Turbulent flow of non-Newtonian systems," AIChE Journal, vol. 5, no. 2, pp. 189-204, 1959.

[4] K. Gasljevic, G. Aguilar, and E. Matthys, "On two distinct types of drag-reducing fluids, diameter scaling, and turbulent profiles," Journal of Non-Newtonian Fluid Mechanics, vol. 96, no. 3, pp. 405425, 2001.

[5] E. D. Goddard and K. P. Ananthapadmanabhan, Interactions of Surfactants with Polymers and Proteins, CRC press Boca Raton, FL 1993.

[6] P. Hansson and B. Lindman, "Surfactant-polymer interactions," Current Opinion in Colloid \& Interface Science, vol. 1, no. 5, pp. 604-613, 1996.

[7] I. Harwigsson and M. Hellsten, "Environmentally acceptable dragreducing surfactants for district heating and cooling," Journal of the American Oil Chemists' Society, vol. 73, no. 7, pp. 921-928, 1996.

[8] H. A. AbdulBari, S. N. Kamarulizam, and R. C. Man, "Investigating drag reduction characteristic using Okra Mucilage as new drag reduction agent," Journal of Applied Sciences, vol. 11, no. 14, pp. 2554-2561, 2011.

[9] M. Hellsten, "Drag-reducing surfactants," Journal of Surfactants and Detergents, vol. 5, no. 1, pp. 65-70, 2002.

[10] J. T. Kim, C. A. Kim, K. Zhang, C. H. Jang, and H. J. Choi, "Colloids and Surfaces," A: Physicochem. Eng. Aspects, vol. 391, pp. 125-129, 2011.

[11] K. Gasljevic, G. Aguilar, and E. F. Matthys, "Measurement of temperature profiles in turbulent pipe flow of polymer and surfactant drag-reducing solutions," Phys. Fluids, vol. 19, pp. 083105-1-083105$18,2007$.

[12] J. Lumley, "Drag reduction by additives," Annual Review of Fluid Mechanics, vol. 1, no. 1, pp. 367-384, 1969.

[13] J. Lumley, "Drag reduction in turbulent flow by polymer additives," Journal of Polymer Science: Macromolecular Reviews, vol. 7, no. 1, pp. 263-290, 1973.

[14] A. Metzner and A. Metzner, "Stress levels in rapid extensional flows of polymeric fluids," Rheologica Acta, vol. 9, no. 2, pp. 174-181, 1970 .

[15] K. J. Mysels, "Napalm. Mixture of Aluminum Disoaps," Industrial \& Engineering Chemistry, vol. 41, no. 7, pp. 1435-1438, 1949.

[16] N. J. Kim, J. Y. Lee, S. M. Yoon, C. B. Kim, and B. K. Hur, "Drag reduction rates and degradation effects in synthetic polymer solution with surfactant additives," J. Ind. Eng. Chem. vol. 6, pp. 412-418, 2000 .

[17] S. Suksamranchit, A. Sirivat, and A. M. Jamieson, "Polymersurfactant complex formation and its effect on turbulent wall shear stress," J. Colloid Interface Sci., vol. 294, pp. 212-221, 2006.

[18] S. Suksamranchit and A. Sirivat, "Influence of ionic strength on complex formation between poly(ethylene oxide) and cationic surfactant and turbulent wall shear stress in aqueous solution," Chem. Eng. J., vol. 128, pp. 11-20, 2007.

[19] C. Tesauro, B. Boersma, M. Hulsen, P. Ptasinski, and F. T. M. Nieuwstadt, "Events of high polymer activity in drag reducing flows," Flow, Turbulence and Combustion, vol. 79, no. 2, pp. 123-132, 2007.

[20] P. Virk, "Drag reduction fundamentals," AIChE Journal, vol. 21, no. 4, pp. 625-656, 1975.

[21] M. Warholic, H. Massah, and T. Hanratty, "Influence of dragreducing polymers on turbulence: effects of Reynolds number, concentration and mixing," Experiments in Fluids, vol. 27, no. 5, pp. 461-472, 1999.

[22] W. Brostow, S. Majumdar, and R. P. Singh, "Drag reduction and solvation in polymer solutions," Macromol. Rapid Commun., vol. 20, pp. 144-147, 1999

[23] Y. Zhang, J. Schmidt, Y. Talmon, and J. L. Zakin, “Co-solvent effects on drag reduction, rheological properties and micelle microstructures 
of cationic surfactants," J, Colloid Interface Sci., vol. 286, pp. 696790,2005

[24] J. L. Zakin, J. Myska, and Z. Chara, "New limiting drag reduction and velocity profile asymptotes for nonpolymeric additives systems," AIChE Journal, vol. 42, no. 12, pp. 3544-3546, 1996.

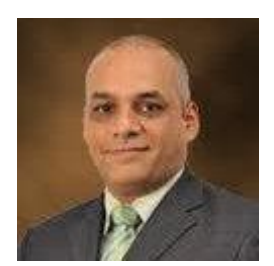

Hayder A. Abdulbari was born in Iraq on September 3, 1973. He got his bachelors of chemical engineering, from Bagdad University, Bagdad, Iraq, in 1996, master of chemical engineering, from Bagdad University, Bagdad, Iraq and $\mathrm{PhD}$ in chemical engineering, Bagdad University, Bagdad, Iraq.

$\mathrm{He}$ is now the director of the "Centre of excellence for advanced research in fluid flow", CARIFF. Also he is an assoc. prof. in the faculty of chemical and natural resources engineering.

Associate Prof. Dr. Hayder A. Abdulbari was awarded for the best achievements in 2012 under "Invention Academics and Education order of Merit", Seoul, South Korea, on 15 December, 2012, Gold Medal in the British Invention Show 2013 for the invention Natural graese, October 2013, Gold Medal For the best invention in industrial equipments in the Invention \& New Product Exposition (INPEX 2011), Pittsburgh, Pennsylvania, USA, 15-17 June 2011, for the Invention entitled "Novel Mechanical Technique to Improve the Flow in Pipes".

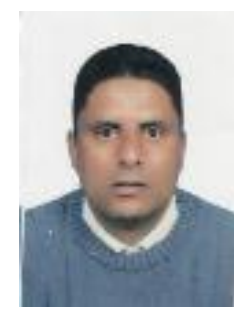

Emsalem Faraj was born in Libya on December 1, 1973. He got his bachelors of chemical engineering from Faculty of Engineering, Al-Mergheb University, Al-Khoms Libya from 1992 to 1998, master of engineering in chemical and process engineering at the Faculty of Engineering, AlMergheb University, Al-Khoms Libya from 2004 to 2007.

$\mathrm{He}$ is now a $\mathrm{PhD}$ student in the Faculty of Chemical and Natural Resources Engineering, Malaysia Pahang. He was a lecturer at the Department of Engineering in chemical and process engineering, Faculty of Engineering, Al-Merghe University Al-Khoms, Libya from 2008 to 2010 . He also was a lecturer at the Department of Chemical Technology, Msallata Higher Technical Institute, Msallata, Libya from 2008 to 2010.

Emsalem Faraj Hawege has won a silver award two times. They are Silver Medal for Creation, Innovation, Technology \& Research Exposition 05-06 March, 2014, University Malaysia Pahang and Silver Medal for National, Innovation and Invention Competition Through Exhibition (iCompEx'14) 24-25 March 2014, Politeknik Sultan Abdul Halim Mu'adzam Shah, Jetra, Kedah. 